\title{
FRAGMENTO DE PLACA CON INSCRIPCIÓN ROMANA DE Valverde del Camino (Huelva)
}

H. Gimeno Pascual Centro CIL II (UAH) J. A PÉREZ MaCías

Universidad de Huelva

Recibido: $12 / 02 / 2015$

Revisado: 05/03/2015

RESUMEN

En este trabajo se da a conocer una nueva inscripción latina procedente del término municipal de Valverde del Camino (Huelva) y se relaciona con la ciudad romana de Ilip(u)la (Niebla) y la ocupación de su territorio.
Aceptado: 23/03/2015

Publicado: 30/05/2015

\section{ABSTRACT}

This paper presents a new Latin inscription which comes from Valverde del Camino (province of Huelva, southwest Spain) and is related to the Roman city of Ilip(u)la (Niebla) and the occupation of its territory.
Palabras Clave

Roma; Epigrafía; Niebla; Necrópolis.
KEYWORDS

Roma; Epigraphy; Niebla; Cemetery.

* Este trabajo es resultado del proyecto FFI2012-39395-C02-01 concedido por el Ministerio de Economía y Competitividad.

helena.gimeno@uah.es 
El término municipal de Valverde del Camino debió pertenecer en época romana al territorio de Ilip(u)la que confinaba por el Norte con el de las Fodinae de la Faja Pirítica, por el Oeste con el de Onuba, por el Este con el de Ostur y por el Sur con la marisma (figura 1). Los materiales epigráficos encontrados tanto en el oppidum como en su territorium son escasos. En efecto, sólo dos inscripciones pertenecen al oppidum pues descontamos el epígrafe de Fabatus que ya hizo dudar al mismo G. B. De Rossi y cuya antigüedad sigue siendo objeto de polémica (HEp 14, 2005 180; AE 2015, 815; Gimeno, 2006; Maier, 2006; Fernández Martínez, 2007, 279 H2). Una de ellas es un pedestal de estatua de Minerva que se fecha en el siglo II. Rodrigo Caro $(1634,216)$ vio su inscripción ya "muy maltratada"
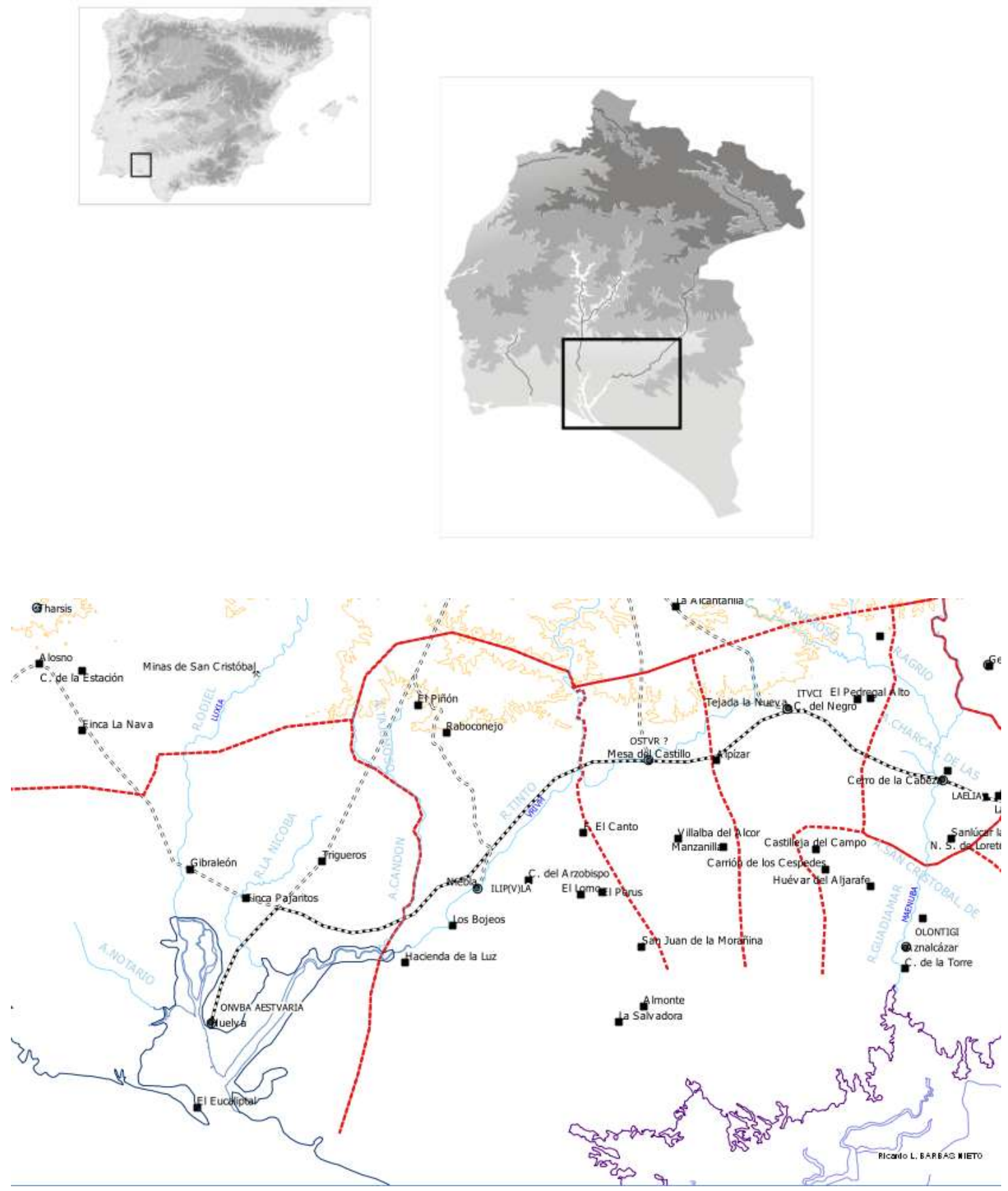

Figura 1. Niebla y los oppida de la campiña de Huelva, con los lugares donde han sido halladas inscripciones. 
en la puerta del Palacio. Hoy está en posición invertida en la Avenida de Jerusalén sosteniendo una placa de bronce, que indica el nombre de la calle. Su superficie está extremadamente desgastada por lo que no sorprende que haya sido publicada dos veces, una dándola por perdida (González Fernández, 1989, 73) que corresponde al texto transmitido por Caro y la otra con una lectura resultado de leer las líneas 2-3 invertidas (González Fernández, 1989, 74). La otra inscripción del oppidum, que fechamos en la segunda mitad del siglo I, está esgrafiada sobre una capa de estuco que recubría un sillar (HEp 12, 2002, 296) y de ella apenas se distinguen completas dos palabras, quondam magno posible reminiscencia de una silva de Stacio (3,2). Del ager Ilip(u)lensis proceden once inscripciones latinas, entre las que contabilizamos como una sola unidad los diversos ladrillos con la inscripción Faustini hallados en El Lomo (véase infra). Estos tituli, entre los que recogemos todos aquéllos producidos hasta el siglo VII, son una columna de mármol con inscripción visigoda hallada en el Cerro de Santa Marina de Raboconejo en término de Niebla (Sánchez Velasco 2010, 131), el ara funeraria del siglo III del Cortijo del Arzobispo en término de Villarrasa (González Fernández, 1989, 76), y un fragmento de inscripción de la finca El Canto en término de La Palma del Condado (González 1989, 80), cuyas únicas tres letras transmitidas, [- - - ]ALE[- - - ], no nos permiten saber ni qué tipo de inscripción era ni su fecha ya que está perdida.

Hacia el Sur, a 2,5 km de Bollullos Par del Condado, en San Juan de la Morañina, se encontró un pedestal redondo (CIL II 955 = González Fernández, 1989, 7) muy machacado como puede verse en el dibujo de Delgado (figura 2), que pudo haber sido llevado al convento de S. Juan de la Morañina desde cualquier otro punto de la región, como ya sugirió Hübner: "verum non nego eum etiam pertinere potuisse ad aliud oppidum antiquum eius regionis" (CIL II, pág. 22). Se trata, como ya explicó Hübner, de una estatua puesta a un emperador de la familia Aelia por un magistrado municipal o un sevir augustal a quien el ordo splendidissimus de una ciudad decreta los ornamenta de más alto grado. Por el calificativo del ordo sería de fines del s. II o inicios del III. No lejos, en los lugares de La Marchenilla y El Lomo se encontraron los ladrillos en los que se lee el nombre Faustinus, que se fechan quizá en el s. V (CIL II 49678). Habría que añadir en esta localidad de Bollullos Par del Con-

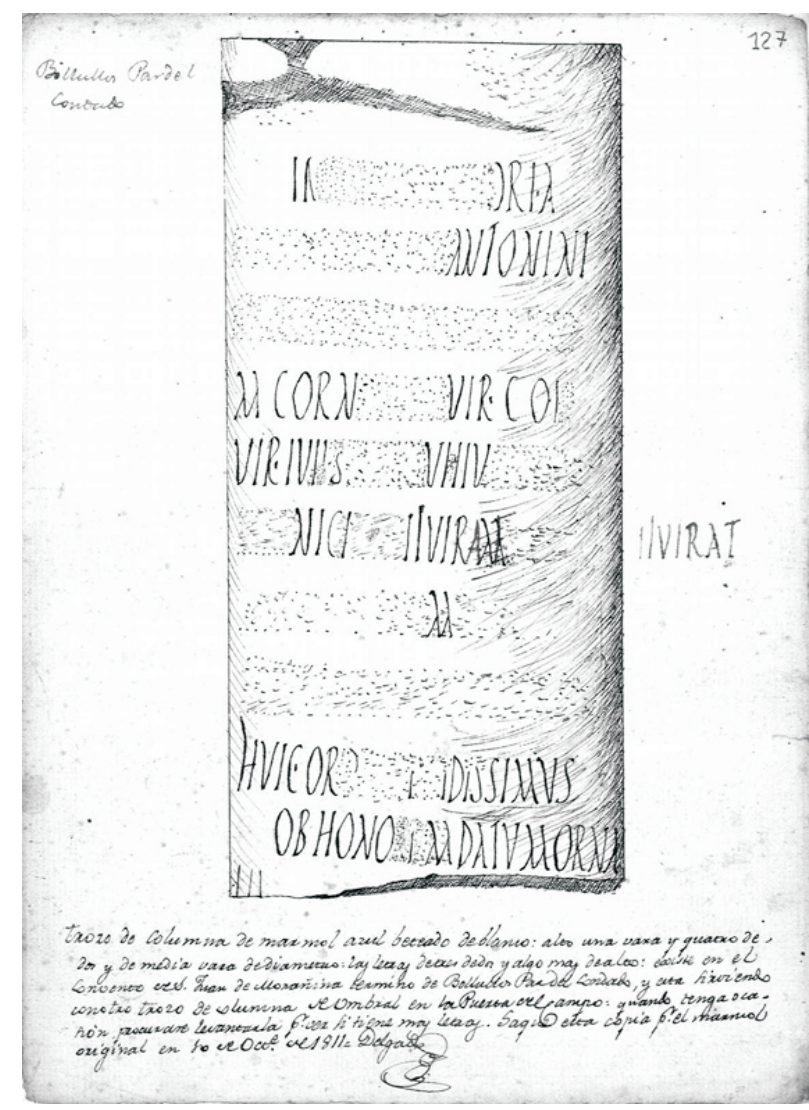

Figura 2. Inscripción de San Juan de Morañina (Bollullos Par del Condado, Huelva).

dado cuatro aras que, según indica González Fernández (1989, 154-156), aparecieron en la iglesia de Santiago apóstol en unas obras realizadas en 1940, de las cuales tres se utilizaron en la fábrica del altar mayor y la cuarta está perdida. Son relevantes para la temprana cristianización de la zona las tapas de sarcófagos halladas en Los Bojeos, término de Bonares (Sánchez Velasco 2010, 119, 120, y 121): la del obispo Vincomalos, fallecido el 2 de febrero del año 509, la de Murensis, de fines del siglo V o inicios del VI, y otra de cuya inscripción solo se conserva la palabra annos. También en Almonte se hallaron dos placas. Una de ellas (González Fernández, 1989, 77), si bien menciona por una cara a Iulia Agrippina, se reutilizó como cancel visigodo como muestra su cara posterior decorada con imbricaciones de semicírculos (Sánchez Velasco 2010, 116). Desconocemos en qué lugar estaría antes de su última función, ya que en las proximidades de Almonte no hay ningún núcleo urbano romano (Pérez Macías, 2004, 89 y 120). La otra es de la tumba de Domigratia, fallecida el 5 de noviembre de 495 


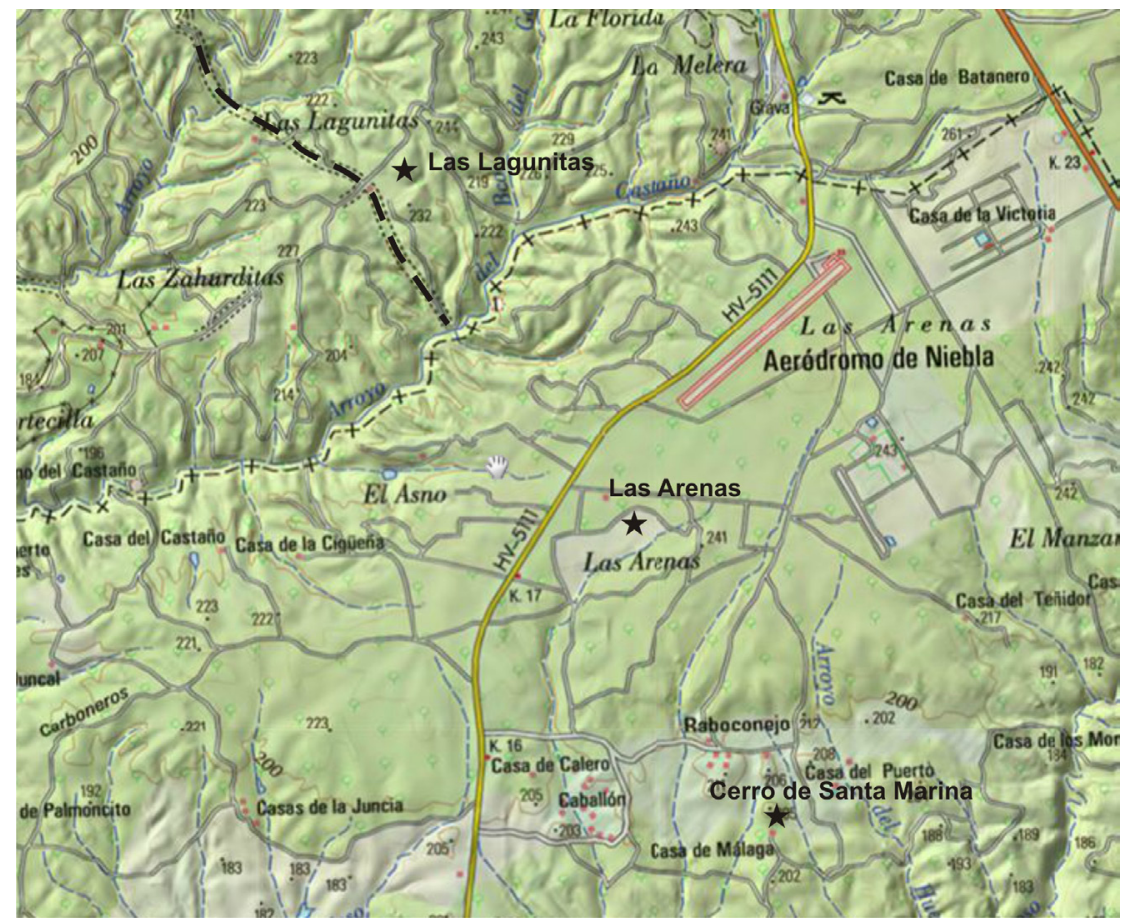

Figura 3. Situación del hallazgo, calzada hacia Niebla y asentamientos del entorno.

(Sánchez Velasco 2010, 115). Completa el conjunto la tessera de Celer Erbuti f., encontrada en las inmediaciones de la Hacienda de la Luz en término de Lucena del Puerto (González Fernández, 1989, 72), del siglo I.

Así pues, cualquier vestigio epigráfico en este territorio, por insignificante que sea, es de gran valor, más aún si es anterior al siglo $\mathrm{V}$, pues es muy llamativo que seis de las inscripciones ilipulenses -casi la mitad- se fechen a partir de dicha centuria, cuando la producción epigráfica había disminuido drásticamente respecto a los niveles de los siglos IIII en todo el Imperio. No es fácil determinar en qué proporción se redujo y, como vemos, depende de las zonas. Beltrán Lloris $(2015,140)$, a partir de los datos incluidos en la Epigraphic Data Base Bari (EDBR) calcula como porcentaje orientativo que las inscripciones cristianas de la ciudad de Roma constituyen un 30\% del número total de inscripciones de esta ciudad. Téngase en cuenta, naturalmente, que en Roma se produjeron muchísimas más que en otros lugares de Occidente y también más temprano.

La inscripción que damos a conocer se encontró en la zona de El Piñón, en el sitio de Las Lagunitas, término municipal de Valverde del Camino, junto al Arroyo del Castaño y a los restos del camino romano que se dirigía hacia Niebla (figura 3). Este camino se desvía de la vía romana de Urium a Onuba a la altura del polígono industrial de Valverde del Camino, desde donde se puede seguir en su recorrido, pero se pierde parcialmente después de atravesar el Arroyo del Castaño debido a los aterrazamientos de las plantaciones de eucaliptos. Fue encontrada por el propietario de la finca, José Andrés Rivera Becerro, quien la mostró a Juan Carlos Castilla Soriano, que nos informó del hallazgo e hizo todas las gestiones para que pudiéramos realizar su autopsia ${ }^{1}$. La inscripción se encuentra ya en los fondos del Museo de Huelva.

En esta área se ha constatado un denso poblamiento rural de época romana. Entre los asentamientos conocidos de esta zona se encuentran los de Las Arenas y Raboconejo (figura 3). El de Las Arenas está formado por una villa rústica y su área de necrópolis, en la cual se encontró un tesorillo formado por unos 800 antoninianos que se extienden entre los principados de Gordiano III y Galieno, de la segunda mitad del siglo III d.C., que se ha relacionado con el problema de las invasiones

1 A quienes queremos manifestar desde aquí nuestro más sincero agradecimiento por las facilidades brindadas para poder llevar a cabo su estudio. Nuestro agradecimiento también a Luis Marín Santos por sus fotografías. 


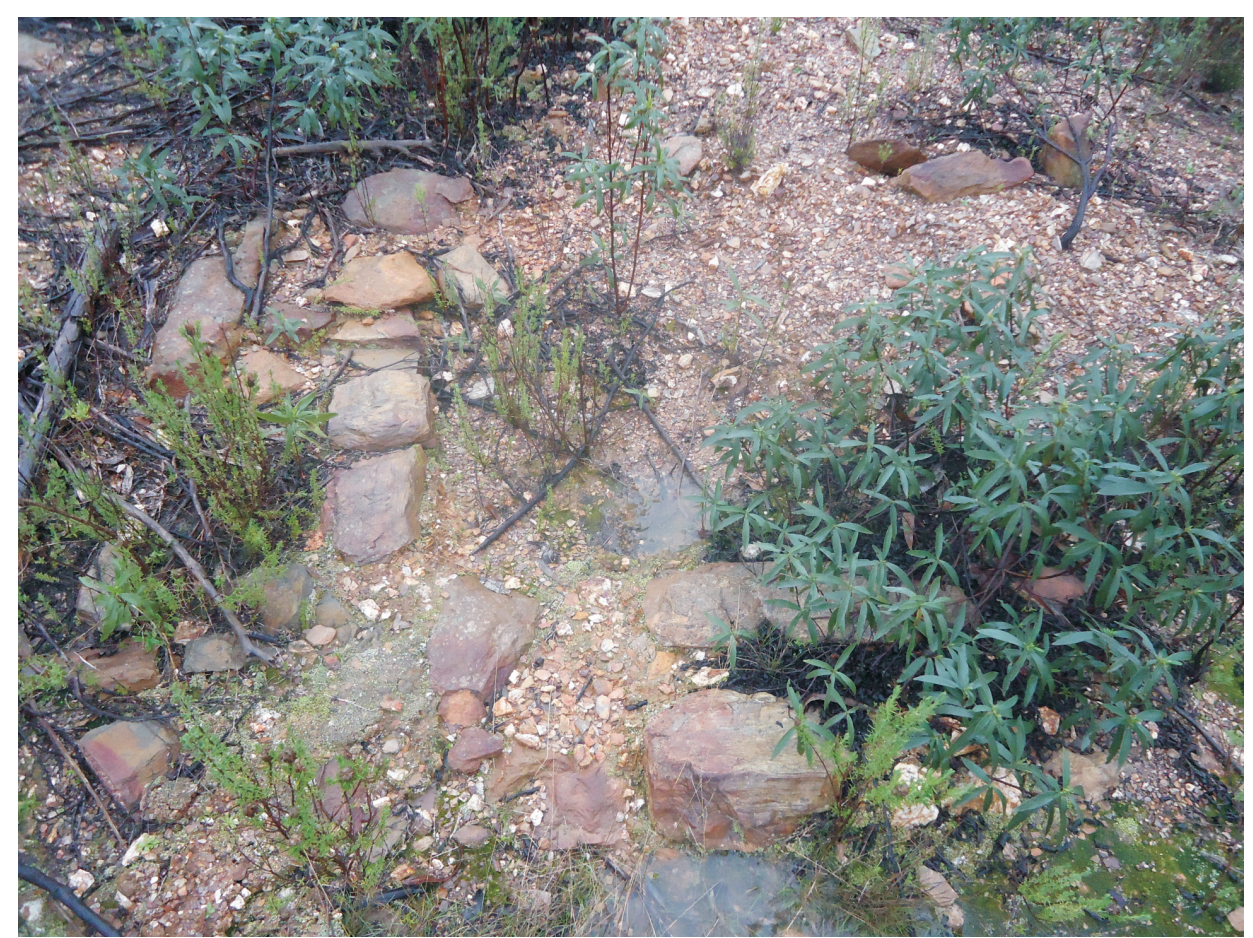

Figura 4. Restos constructivos de Las Lagunitas (Valverde del Camino).

germánicas de este momento (Balil Illana, 1957). De Raboconejo procede la inscripción de época visigoda del Cerro de Santa Marina ya indicada (Sánchez Velasco, 2010, 131), y los restos parecen corresponder a un edificio identificable con una pequeña basílica rural, que a juzgar por los materiales de superficie, entre ellos un fragmento de fondo de un ataifor de la especie verde y manganeso, seguiría en uso por lo menos hasta época califal.

La situación exacta del hallazgo de Las Lagunitas se encuentra definida por las siguientes coordenadas UTM de Huso 29: X-700048/Y-4153146. En este sitio se pueden observar todavía en superficie algunos muros de mampostería (figura 4), en algún caso haciendo esquina en ángulo recto, y escasísimos elementos de cubrición de época romana (tégulas). Los mampuestos proceden de la zona y su factura es cuidada, aunque con un simple mortero de barro. Una exploración atenta de toda la zona nos permite proponer que no se trata de los restos de un asentamiento rústico, pues parece dibujarse solo un pequeño edificio de planta cuadrangular.

La placa de la inscripción es de caliza, bien pulida, y parece que está rota por todos sus lados, aunque también pudiera haber sido recortada para su reaprovechamiento. Mide de alto $7,5 \mathrm{~cm}$, de ancho $5 \mathrm{y}$ tiene un grosor de $2 \mathrm{~cm}$. Algunos arañazos en la parte inferior certifican que ha sido removida por el arado. Las letras, librarias, de no muy buena factura, tienen una altura de $2 \mathrm{~cm}$. Lo que ha quedado del texto dice (figura 5):

$$
[---] \text { ORVM }[---]
$$

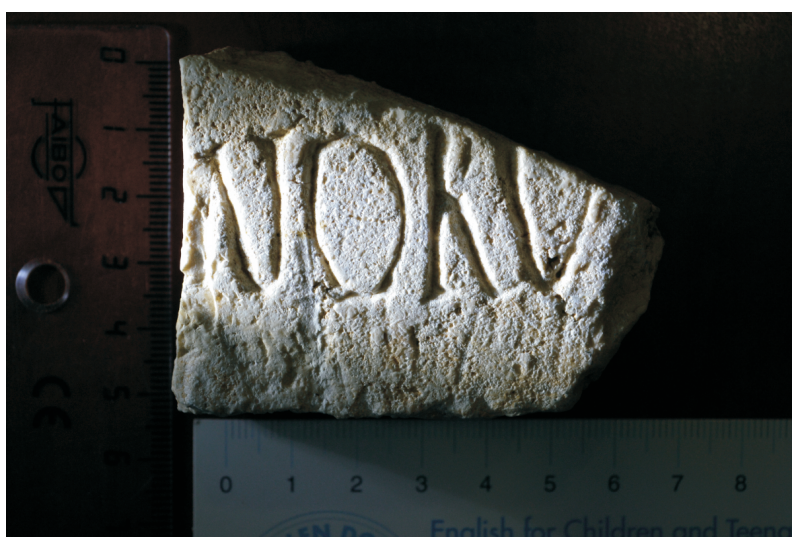

Figura 5. Placa con inscripción de Las Lagunitas (Valverde del Camino). 

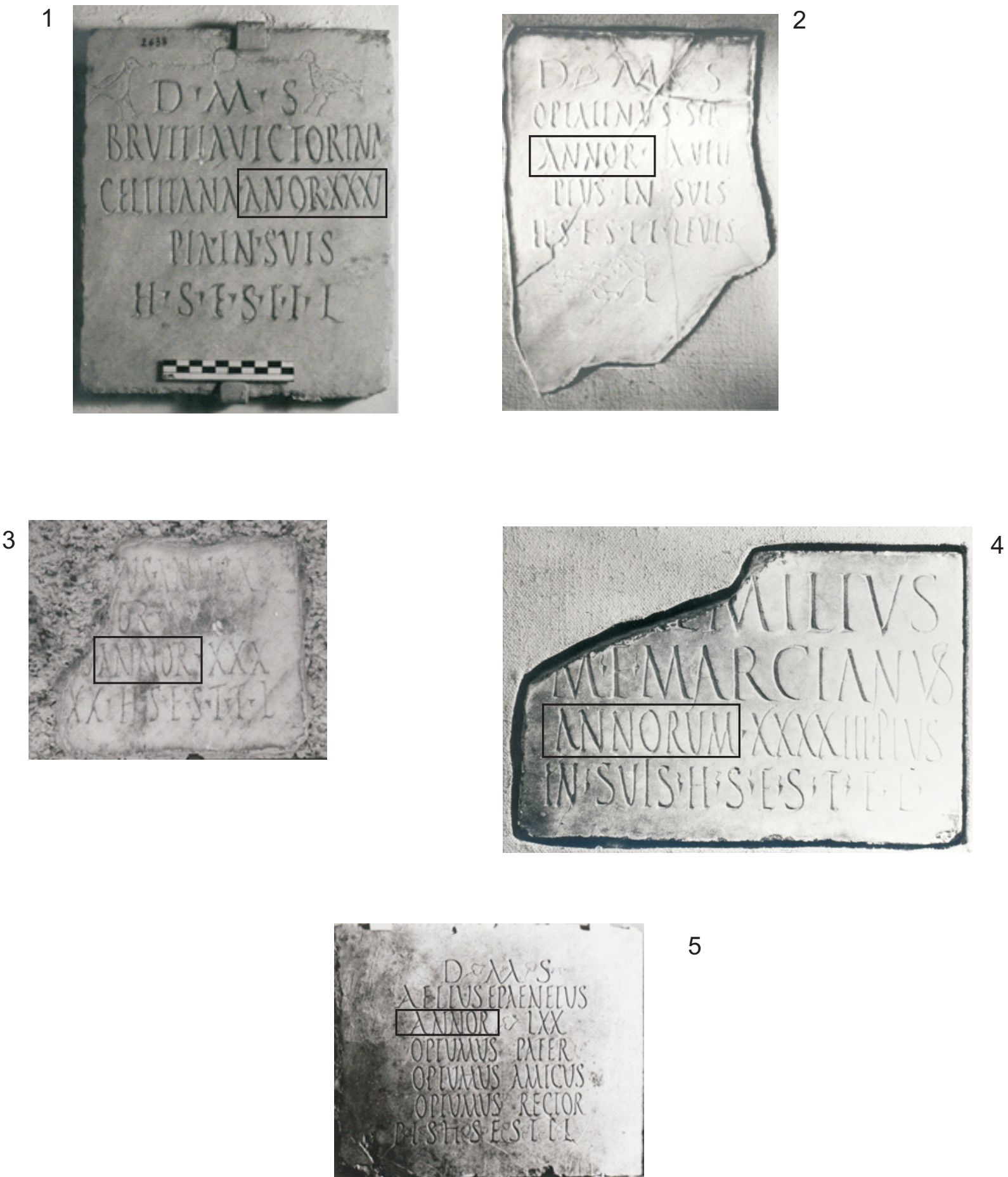

5

Figura 6. Inscripciones de Celti (1 a 4) y Canania (5). Archivo Fotográfico Centro CIL II (UAH). Fotos H. Gimeno y A. U. Stylow. 
Esta terminación es el final de un complemento nominal en plural, cuyo inicio podría suplirse de variadas formas. Podríamos pensar en el nombre de los habitantes de una comunidad cívica (res publica/ordo etc. [---]orum), en una unidad militar (alae/cohors ... [---]orum) o en cualquier asociación (collegium [---]orum) por mencionar algunas posibilidades. Sin embargo, por razones estadísticas, así como por el tipo de soporte, una placa, muy común en los enterramientos de la zona occidental del valle del Guadalquivir, lo más probable es que estas letras pertenezcan a la indicación de la edad de un difunto o difunta escrita por entero [ann]orum. Si bien es más normal su utilización abreviada en AN o ANN, de mil quinientas cincuenta inscripciones de la Bética en las que se indica la palabra annorum consultadas en la Data Base Clauss-Slaby, seiscientas noventa y siete lo hacen con la abreviatura ann(orum), setecientas cuarenta y cuatro con an(norum) y las ciento nueve restantes lo indican con la palabra annorum completa, forma que suele utilizarse con posterioridad a las formas abreviadas.

Así, en el supuesto de que hubiera sido el enterramiento de un solo difunto -lo más habitualy sin dedicante el texto podría haber tenido una estructura similar a esta:

Nombre del difunto en nominativo

[ann]orum + cifras del numeral (+ adjetivos o fórmula del tipo pius in suis?)

$h(i c) \cdot s(i t u s) \cdot e(s t) \cdot s(i t) \cdot t(i b i) \cdot t($ erra $) \cdot l($ evis $)$

Tanto para el tipo de monumento, como para la forma de las letras y la palabra desarrollada annorum tenemos paralelos muy cercanos en el valle del Guadalquivir a partir de mediados del siglo II, en Celti (González 1991/96, 177, González 1991/96, 173, González Fernández, 1991/96, 190; González 1991/96, 201, 563) o en Canania (González 1991/96, 249), por mencionar algunos casos (figura 6). Así, fecharíamos esta inscripción en la segunda mitad del siglo II o a comienzos del III. En relación con la escasa entidad de los restos constructivos y el formulario de la inscripción pensamos que el yacimiento puede ser un área de necrópolis formada por un pequeño mausoleo en forma de casa, de tipo parecido al excavado en Punta del Moral en Ayamonte (Del Amo y de la Hera, 2003).
BiBLIOgRAFÍA

Balil Illana, A. (1957), "Las invasiones germánicas en Hispania durante la segunda mitad del siglo III d.C.", Cuadernos de Trabajo de la Escuela Española de Historia y Arqueología en Roma, 9, 119-180.

Beltrán Lloris, F., (2015), "Latin Epigraphy: The Main Types of Inscriptions", The Oxford Handbook of Roman Epigraphy (Ch. Bruun y J. Edmondson, Eds.), Oxford, 89-110.

Caro, R., (1634), Antigüedades y principado de la illustrissima ciudad de Sevilla y Chorographia de su Convento Juridico, Sevilla.

CIL II, Corpus Inscriptionum Latinarum, vol. II. Inscriptiones Hispaniae Latinae, ed. Ae. Hübner, Berolini 1869; Supplementum, Berolini 1892.

Del Amo y de la Hera, M. (2003), Panteón familiar romano en isla Canela (Ayamonte, Huelva), Huelva.

Fernández Martínez, C. (2007), Carmina Latina Epigraphica de la Bética Romana. Las primeras piedras de nuestra poesía, Sevilla.

Gimeno Pascual, H. (2006), ““Italia latens”: la contribución italiana al desarrollo de la Epigrafía en España en el siglo XIX”, Arqueología, coleccionismo y antigüedad: España e Italia en el siglo XIX (J. Beltrán Fortes, B. Cacciotti y B. Palma Venetucci, Eds.), Sevilla, Universidad de Sevilla, 217-242

González Fernández, J. (1989), Corpus de Inscripciones Latinas de Andalucía I, Huelva, Sevilla.

(1991), Corpus de Inscripciones Latinas de Andalucía II, Sevilla I. La Vega (Hispalis), Sevilla II. La Vega (Itálica), Sevilla.

(1996), Corpus de Inscripciones Latinas de Andalucía II, Sevilla III. (La Campiña), Sevilla IV. El Aljarafe, Sierra Norte, Sierra Sur, Sevilla.

HEp, Hispania Epigraphica.

Maier Allende, J. (2006), “Aureliano FernándezGuerra, Giovanni Battista de Rossi y la arqueología paleocristiana en la segunda mitad del siglo XIX”, Arqueología, coleccionismo y antigüedad: España e Italia en el siglo XIX (J. Beltrán Fortes, B. Cacciotti y B. Palma Venetucci, Eds.), Sevilla, Universidad de Sevilla, 299-349. 
Pérez Macías, J. A., (2004), “Arqueología del Cristianismo primitivo en Huelva", Ave verum Corpus. Cristo Eucaristía en el arte onubense (M.J. Carrasco Terriza, Coord.), Córdoba.

Sánchez Velasco, J., (2010), "El antiguo obispado de Niebla (Huelva). Nuevas aportaciones a su topografía arqueológica: territorio, arquitectura y liturgia”, Huelva Arqueológica 22, 97-136. 